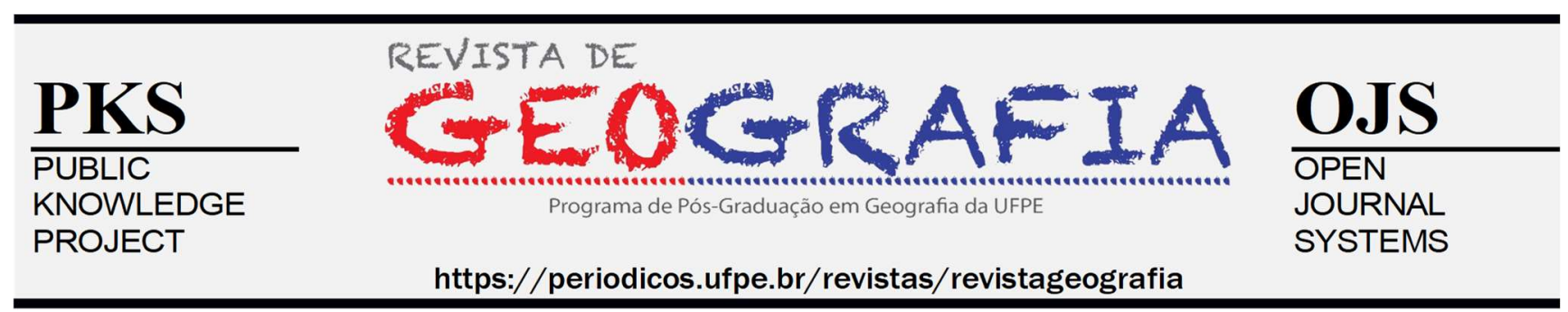

\title{
TERRITÓRIO, TERRITORIALIDADE E ESPACIALIDADE KAINGANG NO SUL DA BACIA HIDROGRÁFICA DO RIO TAQUARI-ANTAS, RIO GRANDE DO SUL/BRASIL
}

\author{
Jonathan Busolli ${ }^{1}$, Luís Fernando da Silva Laroque ${ }^{2}$ \\ ${ }^{1}$ Mestrado em Ambiente e Desenvolvimento e Graduação em História pela Universidade do Vale do Taquari- Univates. \\ Professor da Educação Básica Municipal de Arroio do Meio/RS Email: jbusolli@universo.univates.br \\ ${ }^{2}$ Doutorado em História. Professor e pesquisador do Programa de Pós-Graduação em Ambiente e Desenvolvimento e do \\ Curso de Graduação em História da Universidade do Vale do Taquari-Univates/RS. E-mail: lflaroque@univates.br. O \\ estudo insere-se no Projeto de Pesquisa "Identidades étnicas em espaços territoriais da Bacia Hidrográfica do Taquari- \\ Antas/RS” e Projeto de Extensão "História e Cultura Kaingang”, vinculados ao Programa de Pós-Graduação em Ambiente \\ e Desenvolvimento e contou com auxílio financeiro da Univates, do PROSUC/CAPES e da FAPERGS.
}

Artigo recebido em 28/06/2020 e aceito em 17/11/2020

\begin{abstract}
RESUMO
As regiões de planalto do Brasil meridional constituem-se em espaços de tradicional ocupação de indígenas Kaingang. Mesmo expulsos dos tradicionais espaços territoriais, os Kaingang jamais deixaram de circular por seus territórios e a partir da segunda metade do século XX, passaram a empreender um processo de retomada das suas terras que dará origem à Terra Indígena Pó Mág, localizada na porção sul da Bacia Hidrográfica Taquari-Antas. O objetivo do estudo constitui-se em analisar como os Kaingang da Terra Indígena Pó Mág, percebem os elementos que constituem o lugar, a territorialidade e a espacialidade do grupo. Para tanto, o método do estudo é o qualitativo e contou com a análise de conteúdo e a abordagem ligada à etno-história e a história ambiental para a análise dos dados oriundos do levantamento documental, da história oral e dos procedimentos etnográficos. Como resultados, aponta-se que a Terra Indígena Pó Mág é dotada de uma espacialidade e de dinâmicas próprias, que a aproximam de um espaço enquanto lugar, dotado de significações características e do sentimento de pertencimento.
\end{abstract}

Palavras-chave: Kaingang; Territorialidade; Terra Indígena; Rio Grande do Sul.

\section{TERRITORY, TERRITORIALITY AND SPACIALITY KAINGANG THE SOUTH OF THE TAQUARI-ANTAS RIVER BASIN, RIO GRANDE DO SUL/BRAZIL}

\begin{abstract}
The plateau regions of southern Brazil constitute spaces of traditional occupation of Kaingang natives. Even though they were expelled from the traditional territorial, the Kaingang never ceased to move through their territories, from the second half of the twentieth century began to undertake a process of resumption of their land that originates from the lack of physical space in the indigenous areas located in the north. The Pó Mág Indigenous Land, located southern portion of the TaquariAntas Hydrographic Basin, originates from this process and has been undertaking the construction of its territoriality in the indigenous land space. The purpose of the study is to analyze how the Kaingang of the Pó Mág Indigenous Land perceives the elements that constitute place, territoriality and spatiality in the local space. In order to do so, the method of the study is
\end{abstract}


qualitative and counted on the analysis of content and the approach related to ethnohistory and environmental history regarding the investigation of the documentary survey and the data obtained through oral history and procedures ethnographic. As results, based on theoretical contributions of territoriality and ethnicity, it was pointed out that the Pó Mág Indigenous Land is endowed with a spatiality and its own dynamics, which bring it closer to a space as a place, endowed with characteristic meanings and the sense of belonging.

Keywords: Kaingang; Territoriality; Indigenous Land; Rio Grande do Sul.

\section{INTRODUÇÃO}

A Terra Indígena Pó Mág, localizada no munícipio de Tabaí, no Rio Grande do Sul, integra os espaços tradicionalmente ocupados pelos Kaingang, constituído pelas áreas de planalto da região sul do Brasil, cobertas em grande parte por florestas de Araucária. Esses espaços de ocupações indígenas Kaingang se expandem em direção ao sul a partir da Bacia Hidrográfica do Rio Tietê, no estado de São Paulo, alcançando os estados de Paraná e Santa Catarina, até os territórios limítrofes do delta do Rio Jacuí, no estado do Rio Grande do Sul (Laroque, 2009).

Mesmo expulsos dos tradicionais espaços territoriais a partir de meados do século XVIII e durante o século XIX, os Kaingang jamais deixaram de circular por seus territórios. No Rio Grande do Sul a partir da segunda metade do século XX passaram a empreender um processo de retomada das suas terras que se origina a partir da falta de espaço físico nas áreas indígenas localizados ao norte em virtude do contínuo crescimento demográfico da população. Com isso, os Kaingang intensificaram suas movimentações pelos tradicionais territórios, agora ocupados por áreas de contexto urbano como, por exemplo, as áreas ao sul da Bacia Hidrográfica do Rio Taquari-Antas, onde viviam no século XIX, sendo ilustrativo desse processo a criação das terras indígenas Kaingang Jamã Tÿ Tãnh e Foxá, respectivamente localizadas nos municípios de Estrela e Lajeado.

Esse processo gerou uma série de desencontros culturais entre os indígenas Kaingang e não indígenas, que será maximizado a partir do início das obras de duplicação da rodovia BR 386, no ano de $2010^{1}$, uma vez que a execução do empreendimento atingiu diretamente a Terra Indígena Jamã Tÿ Tãnh, em Estrela e indiretamente a Terra Indígena Foxá, em Lajeado. Estudos antropológicos e ambientais foram produzidos visando avaliar os impactos que as obras de duplicação da rodovia causariam não só aos indígenas Kaingang, mas também aos demais moradores atingidos.

Nesse processo, no ano de 2013 é fundada a Terra Indígena Pó Mág localizada no município de Tabaí, em uma área de terras disponibilizada como parte das medidas compensatórias para Terra Indígena Foxá. Nesta nova área, os Kaingang buscam dar continuidade à sua identidade étnica, cultural

\footnotetext{
${ }^{1}$ Com vista a fomentar o desenvolvimento econômico da Região do Vale do Taquari/Rio Grande do Sul, a duplicação da BR 386 recebeu investimentos do Programa de Aceleração do Crescimento (PAC) do governo federal. Mas como o empreendimento atingiu diretamente uma comunidade Kaingang e indiretamente seis, o EIA/RIMA exigiu medidas compensatórias e mitigatórias, dentre as quais a aquisição de terras.
} 
e linguística enquanto empreendem a construção de uma apropriação simbólica dos elementos constitutivos daquele espaço, ressignificando os novos elementos, construindo sua territorialidade. Neste sentido a questão proposta é de que maneira a comunidade da Terra Indígena Pó Mág, em seu processo de retorno aos seus tradicionais territórios na Bacia Hidrográfica do Taquari-Antas passou a constituir categorias como lugar, territorialidade e espacialidades e as relações interétnicas com a comunidade envolvente. O objetivo do estudo constitui-se em analisar como os Kaingang da Terra Indígena Pó Mág, percebem os elementos que constituem o lugar, a territorialidade e a espacialidade no espaço local, bem como suas relações com a sociedade envolvente.

A metodologia utilizada no estudo foi a abordagem da etno-história e a história ambiental. Segundo Cavalcanti (2011), a intenção da etno-história, metodologia criada pela Sociedade Americana de Etnografia, era criar a possibilidade de uma história que fosse desenvolvida por meio de dados etnográficos dos povos indígenas do pós-contato. Porém, a etno-história, com a inclusão dos registros arqueológicos tornou-se mais holista e passou a discutir também o espaço temporal do pré-contato.

A história ambiental por sua vez, movimenta-se em meio ao reino humano das narrativas, em busca da máxima objetividade possível com vista a demonstrar como o ser humano em espaços e temporalidades distintas tem vivido e utilizado os recursos naturais. Para isso, é preciso reconhecer que os atos do ser humano acontecem dentro de uma rede de relações de dimensões naturais e culturais, buscando identificar os termos relacionais entre sociedade e natureza, dicotomia construída com base na subjetividade ocidental (Espindola, 2012).

A forma de abordagem é a qualitativa, pois tem o ambiente natural como fonte de dados e busca construir uma análise descritiva em um viés holista, compreendendo as relações e os significados delas. Os procedimentos técnicos abordados foram a revisão bibliográfica sobre os indígenas Kaingang e pesquisa documental no Ministério Público Federal, em Porto Alegre, e na Câmara de Vereadores do Município de Tabaí.

Recorreu-se ainda a pesquisa de campo com os Kaingang da Terra Indígena Pó Mág, em Tabaí valendo-se de procedimentos etnográficos e da história oral. Conforme Uriarte (2012), o primeiro se trata de um método antropológico e caracteriza-se a partir da convivência com o grupo pesquisado, já a história oral, segundo Vansina (2010), tem por objetivo levantar elementos da tradição como crenças, mitos e histórias às gerações mais novas. Tendo em vista a etno-história ser uma abordagem interdisciplinar dialogou-se com a história, antropologia, arqueologia e biologia considerando as fontes bibliográficas e documentais, bem como os dados etnográficos, arqueológicos e orais pesquisados que foram analisados com base em aportes teóricos da territorialidade e da etnicidade. 


\section{A TERRA INDÍGENA PÓ MÁG ENQUANTO LUGAR DE VIVÊNCIA KAINGANG}

Fundada no ano de 2013 como um desdobramento da Terra Indígena Foxá/Lajeado a partir da iniciativa de seu primeiro cacique, Francisco Rokàg dos Santos², a Terra Indígena Pó Mág localiza-se no município de Tabaí, porção sul da Bacia Hidrográfica do Rio Taquari-Antas ${ }^{3}$. O espaço abriga uma população de cerca de 40 pessoas, são liderados pelo Cacique André Fongue e conta atualmente com cinco casas, uma igreja, um galpão para a confecção de artesanato, um açude e um campo de futebol. Segundo cópia de memorial descritivo do Departamento de Meio Ambiente do Município de Tabaí presente no Inquérito Civil no 1.29.000.002074/2014-11 (Brasil, 2014), a área que atualmente compõe a Terra Indígena Pó Mág é formada por 14 hectares, localizados em parte do morro conhecido como Pedra Branca $^{4}$ e caracterizada como Área de Proteção Permanente (APP). O recorte espacial da região é similar às delimitações da microrregião sul do Vale do Taquari ${ }^{5}$. A vegetação local está inserida no bioma da Mata Atlântica, sendo composta principalmente por floresta estacional decidual na porção central e meridional da região, e por floresta ombrófila mista na porção setentrional (Kreutz; Machado, 2017).

Em seus estudos sobre o espaço, Milton Santos (Santos, 1996), chama a atenção que em cada período histórico o espaço geográfico muda juntamente com o tempo, portanto a análise do espaço precisa acompanhar estas transformações e revitalizadas. $\mathrm{O}$ “[...] o espaço tem um papel privilegiado, uma vez que ele cristaliza os momentos anteriores e é o lugar de encontro entre esse passado e o futuro, mediante as relações sociais do presente que nele se realizam" (SANTOS, 1994, p. 122).

No que se refere ao território, conforme ainda Milton Santos, trata-se do lugar geográfico de excelência, tendo em vista ser a base material sobre a qual uma sociedade produz a sua história. Corroborando na questão, conforme enfatiza Espindola (2015), o lugar é o espaço onde acontece a concretude do existir e do realizar, enquanto o território é construído a partir da ação dos atores, seja individualmente ou coletivamente, a partir do espaço.

Segundo Tuan (2011), o conceito de lugar, diferentemente do conceito de local, possui o caráter subjetivo atrelado. Pensar o lugar é pensar as relações emotivas e ligações subjetivas entre o homem e o meio em que vive, de modo que, conforme Araújo (2013) há entre os conceitos de lugar e território uma relação mútua de complementaridade.

\footnotetext{
${ }^{2}$ Francisco Rokàg dos Santos foi cacique da Terra Indígena Pó Mág desde sua fundação em 2013 até meados do ano de 2015 , quando faleceu em detrimento de câncer. Em campo levantou-se a grafia Rokàg, utilizada inclusive em trabalho anterior (Busolli, 2016). No entanto, na elaboração da presente pesquisa preferiu-se adotar a grafia Rokàg, conforme utilizado pelo próprio em sua produção bibliográfica.

${ }^{3}$ Coordenadas 2940'30.50'S 51'43'40.80"

${ }^{4}$ Também conhecido como Morro do Meio.

${ }^{5}$ A microrregião sul do Vale do Taquari, segundo o Conselho de Desenvolvimento do Vale do Taquari (CODEVAT), abrange os municípios de Estrela, Bom Retiro do Sul, Fazenda Vilanova, Taquari e Tabaí (CODEVAT, 2017).
} 
Segundo Espindola (2012), território pode ser tratado a partir de duas perspectivas, uma materialista e outra subjetiva. Na primeira, o território é percebido como algo objetivo, limitado fisicamente e que garante abrigo e recursos, abrangendo, portanto, aspectos políticos e econômicos. Em sua perspectiva subjetiva, o território é o espaço das relações sociais, dotado de referências identitárias, simbólicas e de valor. O objeto de análise em tal perspectiva são os locais inter-relacionados, os percursos e seus pontos importantes, abarcando o sentimento de pertencimento e de afetividade dos indivíduos para com espaço e tem na fenomenologia seu suporte teórico de análise.

Entre os indígenas Kaingang, segundo Rosa (2005), o território é composto de domínios/lugares Xamânicos e entrecruzados: nível subterrâneo (espaço onde os antepassados Kaingag teriam permanecido com os ancestrais míticos Kamé e Kayrucré); nível mundo alto (mundo do céu e dos espíritos); e nível da terra (domínio da casa, do espaço limpo e da floresta), onde, respeitando-se a utilização dos recursos naturais, são definidas as zonas para a caça, a coleta, o cultivo e para as redes de relações intra e interaldeã.

Pode-se aproximar o nível terra e suas subdivisões desta configuração espacial Kaingang apontada por Rosa (2005) ao conceito de lugar, pois como já referido, ambos são espaços do cotidiano e das relações sociais e da memória de modo que o conceito de lugar está intimamente ligado ao sentimento de pertencimento a um determinado espaço e à identidade do indivíduo. Ou seja, continuam a acreditar na linguagem dos pássaros, onde a coruja, por exemplo, pode trazer avisos de coisas boas ou não; da taquara, a fibra é utilizada para cestaria; o gomo, para cortar o cordão umbilical dos recémnascidos e seus nós, para contagem do tempo; através do banho no rio, o espírito das águas pode levar os males embora; o etnoconhecimento de plantas como a cancorosa, quina, pitanga, marcela, entre outras, cuja casca, tronco, flores e folhas são de uso medicinal, envolvendo o espírito da mata, portanto presentes em lugares da memória.

A singularidade dos lugares é produzida pelas relações em rede com outras escalas geográficas, quanto mais o lugar se abre para fora, mais se tornam singulares, pois é a partir dele que o mundo é percebido empiricamente (Santos, 2008). As relações comerciais, como a venda de artesanato, e a busca pela obtenção de matérias primas para a confecção do mesmo, protagonizada pelos Kaingang da Terra Indígena Pó Mág, são ligações em rede do lugar com outras escalas como o território.

O lugar, portanto, não é um espaço isolado, mas sim parte de uma rede de relações entre diferentes localizações geográficas que o permite adquirir características próprias, sejam elas afetivas, simbólicas, de pertencimento, entre outras. Conforme Haesbaert (2005), a mobilidade de escalas geográficas presente no conceito de lugar lhe aproxima com o conceito de territorialidade por 
compartilharem a dimensão simbólica e emocional do indivíduo como elemento norteador, o que os diferencia do conceito de território ligado à sua dimensão política. No entanto, para Tuan (2011), os territórios não são simplesmente espaços limitados, mas sim uma rede de caminhos e lugares.

Além disso, os lugares adquirem identidades e significado não só a partir da relação com outras escalas, mas também, segundo Leite (1998), a partir da intenção dos indivíduos e da relação existente entre o espaço e as atividades ali desenvolvidas. Assim, os espaços internos das terras indígenas Kaingang, por exemplo, segundo Tommasino (1995), tornaram-se espaços de reprodução de práticas cotidianas, como os rituais indígenas, as festas contemporâneas e a prática do futebol, portanto espacialidades repletas de significados ligados à identidade.

No entendimento de Colucci e Souto (2011), espacialidade são as formas sociais de apropriação e utilização dos recursos por um grupo em um determinado espaço enquanto que para Ramos (1982), espacialidade pode ser definida como a forma de organização espacial que apresenta características que a diferencia historicamente de outras. Assim, as espacialidades, além de tratarem da questão espacial, dizem respeito às movimentações de um grupo dentro de um determinado espaço ao longo do processo histórico, situação que entre os Kaingang são expressas por categorias com os emã (aldeias) e wãre (acampamentos temporários) dos Kaingang.

Segundo a geógrafa Melina Cabral Machado (2014, p.11-12) “[...] a nomenclatura mais usual dos registros de aspectos culturais é o mapa cultural ou etnomapa, talvez por ter tido pouco espaço na geografia e/ou por ter sido mais trabalhado na antropologia, que desconhecendo a linguagem cartográficas optaram por essa nomenclatura”.

Conforme Barros et. al. (2013), a elaboração de etnomapas cada vez mais detalhados e que apresentam não só suas perspectivas culturais, mas também ecológicas e econômicas. Corroborando na questão Morais, Bethonico e Repetto (2015), reiteram que os etnomapas contribuem para a compreensão das relações que os grupos estabelecem com o meio e com as demais comunidades, além de sua própria organização espacial, esclarecendo todos os fatores da realidade em que vivem. Tratando-se da Terra Indígena Pó Mág, a espacialidade da comunidade Kaingang, cujas representações manifestam suas identidades, estão no etnomapa a seguir (Figura 1). 


\section{Figura 1: Etnomapa da Terra Indígena Pó Mág}

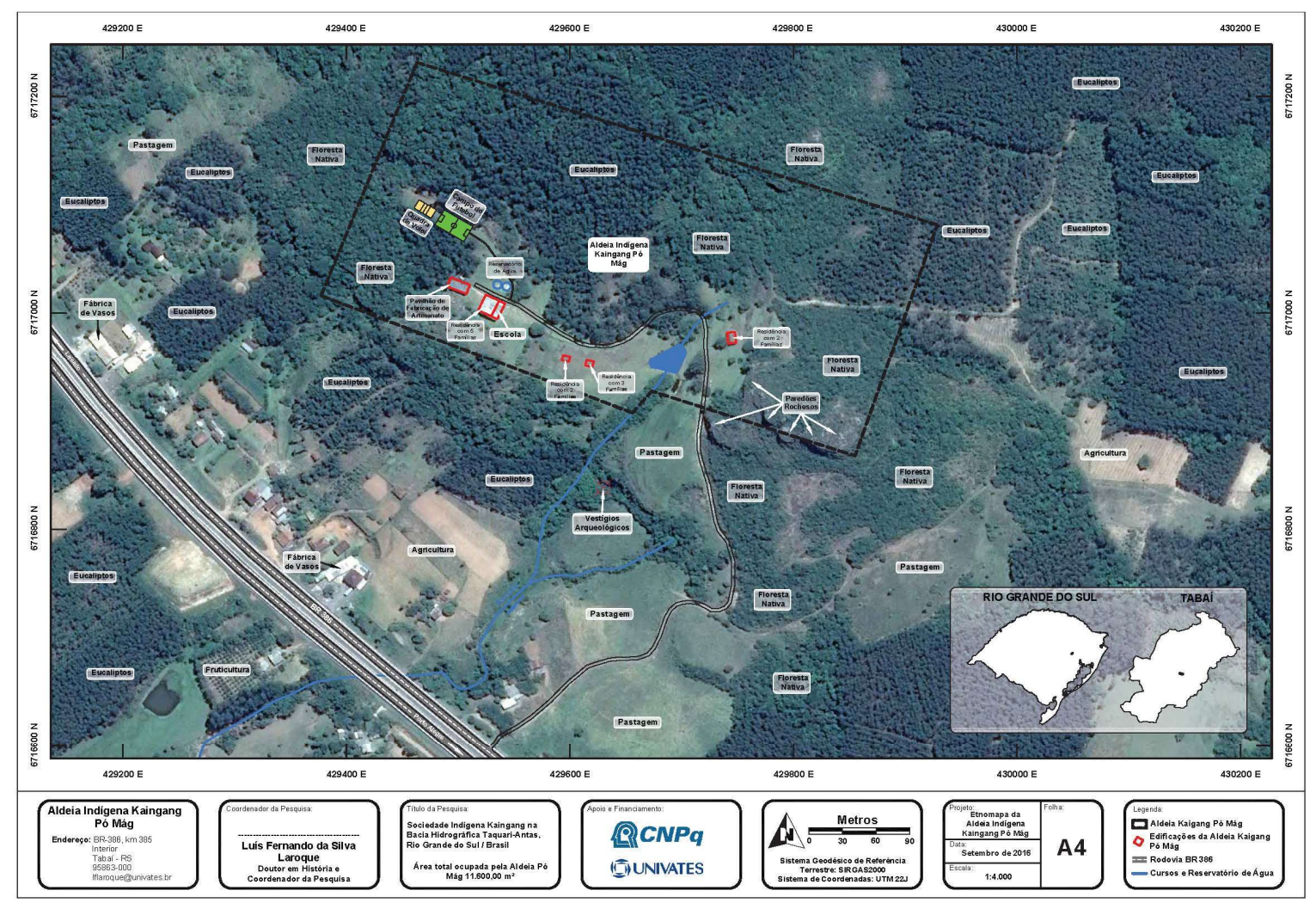

Fonte: Acervo dos Projetos Kaingang da Univates (2016).

Neste sentido, vale salientar que o etnomapa da Terra Indígena Pó Mág fora construído de maneira participativa, onde os indígenas elaboram os mapas com o auxílio técnico de pesquisadores, o que promove empoderamento à comunidade ${ }^{6}$. Na construção do etnomapa em questão todas as representações foram definidas e indicadas pelos próprios Kaingang, os quais consideraram relevante destacar: as residências das famílias, a escola, os reservatórios de água, o campo de futebol, os paredões rochosos, a floresta nativa, o açude, as plantações de eucalipto e os vestígios arqueológicos. Assim, o espaço do campo limpo e o espaço de floresta da Terra Indígena Pó Mág foram apropriados e passaram a ter significados e uma espacialidade própria, o que o torna muito mais que um simples espaço, já que passa a ter o significado de um lugar para a comunidade.

\footnotetext{
${ }^{6}$ Vale salientar que alguns geógrafos também costumam denominar de mapa temático, mas não foi esta opção feita no presente estudo. Informações mais detalhadas sobre representações espaciais e etnomapas indígenas verificar o trabalho de mestrado de Melina Cabral Machado "Mapeamento Cultural e Gestão Territorial de Terras Indígenas: O uso dos Etnomapas" (2014).
} 


\section{A UTILIZAÇÃO DOS ESPAÇOS DA TERRA INDÍGENA PÓ MÁG}

Segundo Tommasino (1995), o espaço físico das terras indígenas representa, historicamente, um espaço de controle exercido pelos não indígenas. Ao mesmo tempo, estes espaços tornaram-se imprescindíveis para os indígenas que podem encontrar ali equipamentos sociais como escolas, postos de saúde, igrejas, escritório da FUNAI, salão de festas, entre outros. Esses espaços de fazem necessários uma vez que o processo de conquista por parte dos não indígenas esgotou dos territórios indígenas as áreas de caça, de coleta e de pesca, transformando a associação com as estruturas do indigenismo uma estratégia de sobrevivência.

Segundo Little (2002), as respostas dos grupos étnicos a esses avanços devem ser interpretadas com cautela, tendo em vista haver acomodação, apropriação, consentimento, influência mútua e mistura, assim como processos de ressignificação. Conforme aponta Libermann (2014), a capacidade do indivíduo de ressignificação de elementos de aspectos do cotidiano ou da memória, possibilita ao ser humano em geral adaptar-se e desvencilhar-se da constante repetição, possibilitando a noção de tempo e impedido a perspectiva da história do sujeito ao determinismo linear.

Esses processos, longos e complexos, resultam na criação dos territórios por parte dos grupos sociais e demonstram que a constituição e a resistência cultural de um grupo são partes de um mesmo processo (Little, 2002). Entre os espaços da Terra Indígena Pó Mág representados no etnomapa (Figura 1), que podem estar sendo pensados a partir de uma perspectiva própria da comunidade, destacam-se a casa principal (residência com cinco famílias), o açude e o campo de futebol.

A comumente denominada casa principal se trata de uma moradia de alvenaria utilizada pelos antigos proprietários da área como sítio. Composta por três quartos, sala, cozinho e uma grande garagem coberta. $\mathrm{O}$ espaço serve de moradia das lideranças e seus familiares e devido a sua amplitude abriga atualmente mais quatro famílias nucleares. A sala da casa atualmente é ocupada pela escola da comunidade, denominada Escola Estadual Indígena de Ensino Fundamental Pó Mág7. A escola, de ensino bilíngue - português/kaingang - atende onze alunos do Ensino Fundamental. O uso da sala da casa principal como escola se dá a partir de um empréstimo do espaço pela Terra Indígena Pó Mág à $3^{\mathrm{a}}$ Coordenadoria Estadual de Educação (CRE), conforme aponta um dos gestores responsáveis pela pasta indígena no mesmo órgão:

Emprestado pela aldeia, não é uma construção do estado. A aldeia tem as suas casas e ela tem uma casa que fazia parte dessa terra conquistada por eles na região, ela é de alvenaria, é uma casa grande que era desse antigo proprietário, um sítio onde tem banheiro, tem vários quartos, tem uma garagem e tem uma sala. Ai a garagem e essa sala da frente ela foi destinada à escola.

\footnotetext{
${ }^{7}$ Ao chegar ao $6^{\circ}$ ano do Ensino Fundamental, as crianças da Pó Mág passam a estudar na Escola Municipal de Educação Básica Carlos Gomes, localizada próxima ao centro urbano de Tabaí (DIÁRIO, 06/09/2018).
} 
Só que a garagem era totalmente aberta, então no verão funcionou e porque a biblioteca ficaria na parte fechada, mas dai chegou o inverno e a gente não conseguiu estruturar a garagem e aí foi toda a escola para essa sala fechada que é uma parceria da comunidade conosco, $3^{\mathrm{a}} \mathrm{CRE}$ (Entrevista Oral 1). ${ }^{8}$

Segundo a mesma gestora (Entrevista Oral 1), a escola conta com quadro, classes de aula, um aparelho de televisão e de DVD, atendendo atualmente doze alunos. As aulas são ministradas por um professor Kaingang, morador da terra indígena, de maneira multisseriada. Também há no espaço uma biblioteca. Quando perguntada sobre o material presente na mesma, a gestora da CRE comentou:

Ela tem. A gente destinou muitos livros para lá, inclusive alguns livros meus pessoais, já que não estou em sala de aula, livros que a gente conseguiu no acervo de outras escolas e tem sim só não temos uma bibliotecária. Tudo na escola hoje depende da ação de fazer desse professor atual (Entrevista Oral 1). ${ }^{9}$

A instalação da escola na terra indígena só fora possível após empenho da comunidade junto ao Ministério Público Federal (MPF). Em reunião realizada no mês de agosto de 2015, representante da Secretária Estadual de Educação (SEDUC) propôs a comunidade que, sobre o aceite da mesma, poderse-ia instalar a escola indígena nas dependências da casa de alvenaria uma vez que a construção de um prédio escolar na comunidade demandaria tempo em virtude da demora em obterem-se recursos e da realização do projeto e das licitações.

Em novembro de 2015, a SEDUC informou ao MPF que havia iniciado o processo de contratação de um professor indígena Kaingang para atuar na escola da Terra Indígena Pó Mág, confirmado em seguida pelo registro de admissão de Misael Natã Carvalho da Silva ${ }^{10}$, presente no Inquérito Civil n ${ }^{\text {1 } 29.000 .002074 / 2014-11 . ~ E m ~ o f i ́ c i o ~ d a ~ S E D U C ~ d e ~ f e v e r e i r o ~ d e ~ 2016, ~ o ~ o ́ r g a ̃ o ~ i n f o r m a ~}$ que esta tramitando processo que visa à construção de um prédio para abrigar a escola indígena da $P o ́$ Mág, e que no momento estava sendo realizado um “[...] levantamento topográfico em subsídio à implantação de projeto arquitetônico do processo da obra" (Brasil, 2014, p. 94).

No entanto, a construção de um prédio para abrigar a escola ainda não foi iniciada, e as aulas continuam sendo realizadas no espaço improvisado de uma das salas da casa principal. Segundo a gestora de educação, essa demora se deve ao fato do receio por parte do poder público de que a comunidade

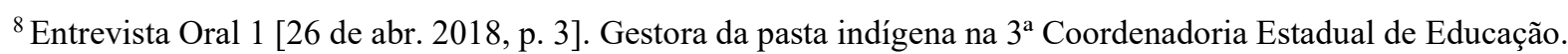

${ }^{9}$ Entrevista Oral 1 [26 de abr. 2018, p. 3]. Gestora da pasta indígena na $3{ }^{\text {a }}$ Coordenadoria Estadual de Educação.

${ }^{10}$ A escolha do professor se dá primeiramente entre as mulheres da comunidade, que em seguida apresentam o nome à CRE. Se este estiver apto a exercer a função (com formação e documentação adequada), é contratado em caráter emergencial pelo órgão (Diário, 08/03/2018).
} 
deixe a terra indígena, demonstrando incompreensão da mobilidade típica dos Kaingang, conforme segue:

Foi um projeto que foi (para a SEDUC) e voltou. Então a gente tem que reabrir ele. A gente depende de todo um contexto porque é uma escola nova. A gente precisa ver a questão de quanto essa aldeia ficara, continuara porque é uma aldeia muito pequena que esta há muito pouco tempo, é uma aldeia que era de Estrela e dai eles foram para lá, daqui a pouco eles decidem ir emborra. Aí pensa o estado começa a construir, é dinheiro público (Entrevista Oral 1).$^{11}$

A garagem da casa principal, como apontado pela gestora (Entrevista Oral 1), também fora em um primeiro momento utilizada como escola. No entanto, as intempéries climáticas, visto que a garagem, apesar de coberta, não é fechada por um portão, obrigaram a mudança para a sala. Nesse espaço, comumente ocorrem reuniões da comunidade, conversas e é onde se recebem as visitas externas (Diário, 06/06/2017). Em diversas ocasiões em campo verificou-se que o espaço também é utilizado para a confecção de artesanato (Diário, 16/01/2017; 25/08/2017; 04/05/2018; 24/05/2018) assim como o galpão localizado nos fundos da moradia.

Na entrada da área da Terra Indígena Pó Mág, próximo aos paredões rochosos que dão nome à comunidade, conforme visto anteriormente, encontra-se o açude. Abastecido com a água advinda de uma pequena nascente localizada no alto do morro circundante, o açude servia para fornecer água aos animais na época do antigo proprietário. Atualmente, no entanto, o espaço é comumente utilizado pelas crianças da comunidade para o lazer (Diário, 14/12/2017).

Conforme aponta Prestes (2018), a relação das crianças com o açude para fins de lazer demonstraria a harmonia construída entre elas e a natureza a partir da reciprocidade e da convivência. Além disso, a nascente que abastece o açude também é utilizada para a realização de "batismos", conforme afirma um interlocutor Kaingang pesquisado (Entrevistado 2) ${ }^{12}$.

Como espaço de lazer, a comunidade também se utiliza de um campo de futebol e de uma quadra de vôlei localizados nos fundos da casa principal, em direção às plantações de eucaliptos. O campo de futebol, além de espaço de lazer da comunidade, também é utilizado em momentos de recreação com outras terras indígenas, conforme ocorrido na festividade do Dia do Índio realizada na Pó Mág no ano de 2017 e que contou com a visita de parentes Kaingang das terras indígenas Por Fi Gâ e Topẽ Pẽn, localizadas respectivamente nas cidades de São Leopoldo e Porto Alegre, que realizaram no campo da Pó Mág um pequeno torneio de futebol, tornando-se um espaço de convívio, não só da

\footnotetext{
${ }^{11}$ Entrevista Oral 1 [26 de abr. 2018, p. 6]. Gestora da pasta indígena na $3^{\text {a }}$ Coordenadoria Estadual de Educação.

${ }^{12}$ Entrevista Oral 2 [06 de set. 2018]. Terra Indígena Pó Mág, Tabaí/RS.
} 
comunidade, mas também das comunidades da região com as quais a Pó Mág mantém laços de parentesco e reciprocidade (Diário, 06/06/2018).

No entanto, o espaço que mais chama atenção dentro da Terra Indígena Pó Mág é a igreja de confissão neopentecostal ligada à Assembleia de Deus que fora erguida ao longo do ano de 2017. A construção da igreja, feita em madeira, contou com a ajuda da administração municipal que contribui com a terraplanagem da área que abriga o espaço. Os próprios Kaingang da comunidade a construíram utilizando-se de madeira disponibilizada por um pastor do município de Tabaí, que também ministra os cultos (Diário, 06/06/2017).

Denominada "Igreja Assembleia de Deus - Congregação Área Indígena", a igreja da Terra Indígena Pó Mág tem seus cultos realizados nas segundas e quintas-feiras, no horário das 19 horas e 30 minutos. O espaço interior, constituído de duas fileiras com três ou quatro bancas de frente a uma parede decorada com um tecido branco, ainda contém um aparelho de som utilizado nos cultos, também utilizado em alguns momentos pelos moradores, principalmente as crianças, como espaço para se escutar música, mesmo profanas (Diário, 05/04/2018). Apesar de ligada a uma denominação neopentecostal, pode-se observar a ressignificação por parte dos Kaingang no que diz respeito àquele espaço, a partir da total ausência de símbolos próprios do neopentecostalismo na igreja ${ }^{13}$ (Diário, 06/06/2017), o que poderia ser tomado como indicativo da conversão ao cristianismo apenas de forma parcial ou aparente.

Os cultos são realizados em português, não contam com divisões de gênero ou de idade entre os participantes (Diário, 06/06/2018). Na interlocução com a liderança da Terra Indígena Pó Mág foi informado que os frequentadores da igreja não são a maioria dos moradores da comunidade, mas que a convivência com religiões cristã vem de longa data, o que ele considera importante, conforme segue:

Olha, não é a maioria, mas as pessoas já sabe. Quando eu tinha uns treze anos... desde que eu
nasci ia na igreja com meu pai. Daí a gente sabe o que apresentam pra nós nessas igrejas, nessas
religião. Nós não somos de religião nenhuma, mas eu vou na igreja também porque faz parte do
bem para nós. Dai hoje não tem outra religião que representa para nós, uma religião que tá vindo,
daí a gente aposta mais. Eu não sou de religião nenhuma mais eu gosto, gosto porque faz bem
pra nós (Entrevista Oral 3). ${ }^{14}$

O fato de grande parte dos Kaingang da Pó Mág seguir uma denominação cristã evangélica não os coíbe de participar de suas festividades tradicionais como se pode acompanhar durante a realização do Kikikoi ${ }^{15}$ na Terra Indígena Foxá em abril de 2018. No entanto, a presença dos Kaingang da Pó Mág

\footnotetext{
${ }^{13}$ Apesar de renegar o uso de imagens, comumente se observa em igrejas neopentecostais dizeres bíblicos, símbolos como a pomba branca ou a palavra "Jesus".

${ }^{14}$ Entrevista Oral 3 [06 de set. 2018, p. 2]. Terra Indígena Pó Mág, Tabaí/RS.

15 Também aparece na literatura com a grafia quiquy ou com o nome de Veingréinyã. Tradicionalmente, o Kikikoi era realizado todos os anos, no entanto, só poderia ser realizado quando houvesse mortos das duas metades, Kamé e Kairu. O
} 
no cerimonial esteve restrita, até onde se pode observar, ao espaço destinado a sociabilidade entre as comunidades a partir dos jogos de futebol, cabo de guerra entre outros, não percebendo a presença de membros da comunidade junto ao espaço onde foram acessos os fogos ${ }^{16}$ (Diário, 07/04/2018).

Para Almeida (2004), o catolicismo estaria mais próximo das crenças de cura dos povos indígenas e da valorização de sua memória oral do que outras denominações cristãs, até porque o catolicismo indígena é indiferente aos dogmas do Vaticano. O chamado catolicismo popular pelo autor (Almeida, 2004), além disso, legitimaria a prática dos kujã , figuras que cumprem um papel central na realização de uma das mais tradicionais cerimoniais Kaingang, o Kikikoi, uma vez que eles são os responsáveis pelos conhecimentos tradicionais ligados à identificação de doenças e de obtenção de remédios a partir das plantas medicinais.

Além disso, percebe-se que a adoção de diferentes formas de religiosidade não substituiu a estrutura exogâmica presente entre os Kaingang da Pó Mág. Desse modo, aparentemente pode-se apontar que: “[...] as diferentes formas de religiosidade ocupam espaço para dar conta de realidades histórico-sociais diferenciadas, marcando a alteridade necessária à reprodução da via sociocultural Kaingang” (Almeida, 2004, p. 115).

Utilizando o exemplo dos Terena, Brandão (1986) aponta que os padrões organizacionais como as metades patrilineares são reafirmadas pelo grupo em seu espaço de vivência que é a aldeia, que se transforma no limite afetivo e relacional do grupo pós-contato com as frentes pioneiras e de expansão. Desse modo, as relações que antes estavam circunscritas ao território, agora dizem respeito apenas ao espaço local. Assim, quando perguntado a respeito das metades exogâmicas, uma liderança Kaingang comentou sobre o funcionamento, conforme segue: “[...] Nós somos Kamé e minha mulher é Kairu. A metade do Kairu é Kamé e aí nossas mulheres são Kairu. Dai nós somos divididos né. Tem meus irmãos casados com Kairu e nós somos Kamé" (Entrevista Oral 3). ${ }^{17}$

A prática do cristianismo na Pó Mág, portanto, assim como em outras terras indígenas Kaingang conforme observado por Almeida (2004), é extremamente complexa pois também representa um ponto de articulação com a cultura Kaingang (como demonstra a ressignificação de elementos da igreja), ou entre os Kaingang e a cidade, podendo a religião cristã entre os Kaingang ser entendida como elo em uma relação entre periferia (a Pó Mág) e centro (a área urbana do município de Tabaí). Sendo assim, as casas, escola, lago e a igreja, tratam-se de espaços da Terra Indígena Pó Mág são pensados e

\footnotetext{
cerimonial tem duração de três dias e no último deles há a ingestão da bebida chamada kiki, que tem a função de impedir os vivos de sentirem medo dos mortos.

${ }^{16}$ No espaço onde é realizado o Kikikoi são acessos três "fogos", um para cada dia da festividade e tem por objetivo afastar a presença dos espíritos durante o cerimonial.

${ }^{17}$ Entrevista Oral 3 [06 de set. 2018, p. 2]. Terra Indígena Pó Mág, Tabaí/RS.
} 
representados pelos Kaingang a partir de uma perspectiva própria do grupo, portanto, a partir da lógica do lugar.

\section{AS RELAÇÕES INTERÉTNICAS ENTRE OS KAINGANG DA PÓ MÁG E A SOCIEDADE LOCAL}

Segundo Tommasino (2016), ao analisar os Kaingang das terras indígenas do oeste do estado de Santa Catarina, percebe-se que sua territorialidade havia avançado para além dos limites oficiais destas áreas. Isso também acontece na Terra Indígena Pó Mág, pois há entre os Kaingang e a sociedade envolvente relações econômicas e de exploração de sua mão de obra por parte dos não indígenas, mas também alianças e a convivência a partir da participação em festas, além dos cerimoniais religiosos e do futebol.

Segundo Almeida (2004), os Kaingang percebem o espaço das cidades como extensão do espaço da aldeia. A venda de artesanato, a utilização de serviços públicos como saúde e educação, o acesso ao comércio, entre outros, são questões que levam os Kaingang a circularem pelas cidades, que dependem de certas condições como oferta de transporte para se deslocar, carregar o artesanato e transportar os doentes.

Conforme ainda Almeida (2004), em relação aos Kaingang das terras indígenas do norte do estado do Rio Grande do Sul, a participação em igrejas e nos eventos por elas organizados também é responsável pela movimentação Kaingang pelas cidades. O contexto descrito pelo autor também pode ser percebido na comunidade Pó Mág, quando estes também se relacionam com os espaços citadinos a partir da política (cobrando dos órgãos públicos o respeito à suas garantias constitucionais), da religião (realizando as atividades religiosas desenvolvidas pelas igrejas), e do esporte (participando de torneios locais de futebol).

Segundo Tommasino (2016), a academia, quando discute as relações entre os indígenas e a sociedade nacional não indígena, quase sempre opta por focar as relações de dominação, de exploração e exclusão. No entanto, esta é apenas uma parte da realidade, pois há uma diversidade de interações interétnica que também incluem o consenso, a adesão e a inclusão. Do mesmo modo, a relação entre Kaingang e outros grupos étnicos é pouco abordada, como a relação com os Guarani, ao qual já existia antes do contato com o não indígena. Desse modo, segundo a autora:

[...] O que se observa é que os Kaingang fazem parte da sociedade local, de forma efetiva, participam de uma rede de sociabilidade ampla e diversificada, de ordem socioeconômica, religiosa, política, historicamente construída ao longo de quase dois séculos. Nesse sentido, é fundamental que as análises históricas sejam acompanhadas da análise da geografia Kaingang e ainda contrapondo-se à história e à geografia da sociedade dominante. [...] (Tomassino, 2016, p. 130). 
A Terra Indígena Pó Mág, localiza-se a cerca de dois quilômetros do centro do município de Tabaí, percurso dificultado em razão de o acesso ser realizado a partir de uma estrada de terra em aclive acentuado, localizada às margens da rodovia BR-386. A proximidade de um centro urbano foi um dos critérios levantados para a escolha da área pela liderança da época, o cacique Francisco Rokàg, para além das questões ligadas à memória do grupo que indicam ser aquela área um antigo wãre, conforme já discutido. A área, como apresentado, foi cedida aos Kaingang como parte das medidas compensatórias das obras de duplicação da rodovia BR-386.

Esta proximidade permite uma relação próxima com setores da sociedade urbana de Tabaí. Cada situação de contato entre indígenas e não indígenas tem suas peculiaridades. Elas podem envolver questões como a posse da terra e seu uso, a luta por direitos, a preservação ou imposição de formas próprias de trabalho, a autonomia ou dependência, entre outros. Estas relações sejam elas de troca, de domínio ou de luta por direitos envolvendo indígenas e não indígenas é denominada por Brandão (1986) como sistema interétnico.

O sistema interétnico que vem se desenvolvendo em Tabaí a partir da relação entre os Kaingang da Pó Mág e a sociedade nacional ali disposta é complexa. Apesar de hoje aparentar ser pacífica, houve momentos em que esta relação estava pautada em desencontros, como a negativa por parte do poder público local, em um primeiro momento, de que as crianças da comunidade fossem matriculadas em uma escola municipal (Busolli, 2016).

Como visto anteriormente, a resolução da situação dependeu de intervenção do MPF, da instalação de uma escola indígena por parte da CRE (órgão de fato responsável pela educação indígena nos anos iniciais) na comunidade e da troca da administração municipal ocorrida em 2017. Atualmente, há dois alunos Kaingang moradores da Pó Mág frequentando os anos finais do ensino fundamental na rede municipal de educação, que garante a eles transporte da terra indígena até a escola (Diário, 27/10/2017).

A religião, conforme apresentado anteriormente, acaba cumprindo um papel importante na aproximação da comunidade com alguns setores da sociedade de Tabaí. A construção da igreja de cunho neopentecostal dentro da área da Terra Indígena Pó Mág, além de ilustrar uma aproximação da maioria dos indivíduos da comunidade para com essa denominação cristã, também demonstra as relações próximas entre a comunidade e figuras políticas do município, uma vez que o pastor que ministra na igreja da comunidade é ligado ao grupo político que atualmente administra o município. Desse modo, a igreja da Pó Mág também pode estar relacionada a uma lógica de alianças, o que explicaria as recentes 
melhorias (terraplanagem, concerto da estrada, transporte escolar, entre outros) realizadas na área e que não ocorriam na administração anterior.

Outro elemento de aproximação da comunidade da Terra Indígena Pó Mág é o futebol. Nos primeiros meses de 2018, membros da comunidade participaram de um torneiro municipal de futebol a partir da formação de um time que recebera o nome de "Cruzeiro" e que contou com a participação inclusive de não indígenas. A partir da participação dos Kaingang em torneios locais do esporte, podese apontar que há a inserção do grupo nas dinâmicas de vivência tabaiense, típicas de qualquer cidade de interior do Brasil.

Da mesma forma, a participação de não indígenas locais no time de futebol formado pelos Kaingang que indica a existência de relações entre a comunidade da Pó Mág e a sociedade local. Esta conjectura pode ser corroborada com a fala de moradores locais, vizinhos (Entrevita Oral 4), colegas de trabalho (Entrevista Oral 5) ${ }^{18}$ e comerciantes do centro urbano de Tabaí (Entrevista Oral 6) ${ }^{19}$ que atestam terem boa relação com os Kaingang da Pó Mág. No entanto, as falas também demonstram certa desconfiança, conforme demonstra a fala de um dos entrevistados ao ser perguntado sobre a relação com os Kaingang: "Por enquanto tá bom. Não tem nada... Mas tá bom” (Entrevista Oral 4). ${ }^{20}$

No entanto, percebe-se processos de invisibilização em relação aos indígenas no município de Tabaí, como demonstra a total ausência de discussão na esfera legislativa local sobre questões relacionadas ao Kaingang. Ao se analisar as atas de registro das sessões da Câmara de Vereadores de Tabaí (entre os anos de 2013 e 2018), observou-se que os problemas vividos pela Pó Mág e suas demandas são completamente ignorados pelos representantes eleitos, uma vez que há apenas uma referência à presença Kaingang no município, mesmo em momentos chave da história da comunidade, como sua fundação, o que demonstra um claro cenário de invisibilização dos Kaingang por parte do poder legislativo local ${ }^{21}$. A exceção é a ata da sessão ordinária de cinco de abril de 2017 (Tabaí, 2017), que registra a discussão sobre projeto de lei que autoriza o repasse de recursos para a realização da festa do índio na Terra Indígena Pó Mág. O projeto fora aprovado, apesar de contestado por alguns dos vereadores.

Curiosamente, a Prefeitura Municipal de Tabaí em ofício de 15 de maio de 2018 enviado ao MPF apresentou uma previsão sobre a normalização do abastecimento de água na Terra Indígena Pó Mág. No documento, o executivo local informou que: “[...] o projeto de lei referente à [...] 'perfuração

\footnotetext{
${ }^{18}$ Entrevista Oral 5 [23 de fev. 2018, 06 p.]. Enfermeira chefe da Secretária de Saúde de Tabaí/RS.

${ }^{19}$ Entrevista Oral 6 [06 de jun. 2018]. Comerciante de Tabaí/RS.

${ }^{20}$ Entrevista Oral 4 [23 de fev. 2018, p. 1]. Morador vizinho da Terra Indígena Pó Mág, Tabaí/RS.

${ }^{21}$ Há algumas referências nas atas da Câmara de Vereadores de Tabaí a um cidadão local conhecido por "Índio", que se averiguou ser um antigo morador da cidade e não possuir relação com a comunidade da Terra Indígena Pó Mág.
} 
do poço tubular da aldeia Kaingang deste munícipio’ foi encaminhado na data de 14 de maio de 2018 para a Câmara de Vereadores de Tabaí-RS” (Brasil, 2014, p. 174). No entanto, tal discussão não fora encontrada nas atas do legislativo, e a comunidade continua sem um poço artesiano (Diário, 19/10/2018). Há entre os Kaingang da Terra Indígena Pó Mág, portanto, assim como entre os povos indígenas de maneira geral, uma demanda por maior representação política, que os possibilite a prática de seus direitos e de sua cidadania.

As relações desenvolvidas dentro dos territórios se operacionalizam em rede, podendo ser caracterizadas a partir da relação da dimensão espacial local com a dimensão mundo quando se leva em consideração a estrutura de relações espaciais discutidas por Milton Santos (Santos, 1996, p. 88) em que o espaço é “[...] a sínteses, sempre provisória, entre o conteúdo social e as formas espaciais”. No entanto, quando se discute esse sistema relacional a partir das relações interétnicas entre Kaingang e não indígenas, deve-se repensar o modelo levando em consideração as dinâmicas próprias dos povos indígenas. Ao se fazer isso, percebe-se que entre os indígenas há um deslocamento dos atributos originais da escala espacial território (entende-se aqui Estado, ou seja, a sociedade nacional não indígena) para a escala mundo, abarcando as relações com o não indígena a partir de questões políticas e econômicas. ${ }^{22}$ A escala território é representada, por sua vez, pelos territórios historicamente construídos, e envolvem a ligação simbólica com o espaço e as relações entre os parentes de diferentes aldeias, enquanto as relações locais se dão de maneira endógena dentro das aldeias. Dessa maneira, as relações Kaingang se deslocam através das três escalas espaciais, condição essencial para sua caracterização enquanto rede.

O contato entre indígenas e não indígenas provocou e continua a provocar alterações em todas as dimensões de vida dos indígenas. Tal fenômeno também pode ocorrer nas relações entre diferentes grupos indígenas, de modo que o fator determinante destas alterações é a relação com o outro e não especificamente com os não indígenas, porém, conforme aponta Brandão (1986), a relação dos povos indígenas com os não indígenas possui outra natureza, pois não são relações entre grupos diferentes, mas desiguais em suas diferenças, imperando os padrões de dominância de uma sobre a outra. Esse contato interétnico se configura como um encontro inevitável marcado pelas perdas sofridas pelos indígenas, mas também como elemento constitutivo de sua alteridade, que através de sua territorialidade, espacialidade e simbologia própria atrelada ao seu território e especificamente ao lugar, promovem a identidade do grupo.

${ }^{22} \mathrm{O}$ que não significa que os povos indígenas não sejam afetadas por processos da globalização. 


\section{CONSIDERAÇÕES FINAIS}

Conforme se pôde perceber, o espaço local da Terra Indígena Pó Mág é dotado de uma espacialidade e de dinâmicas próprias, que a aproximam de um espaço enquanto lugar, dotado de significações características e do sentimento de pertencimento. Essa espacialidade se constitui na relação com o mundo humano e o mundo não humano em suas distintas configurações, tais como o relevo, formações rochosas, as plantas, os animas e os espíritos são elementos que fomentam a cultura Kaingang, enquanto a relação com o humano fomenta a alteridade.

As relações entre os Kaingang e a sociedade não indígena envolvente podem ser ilustradas a partir do uso dos espaços internos da terra indígena e das relações com a sociedade não indígena envolvente. Nesse âmbito, espaços como a escola e a igreja cumprem duplo papel, pois são pensados a partir da lógica própria do grupo, constituindo-se como meios de apropriação de signos do não indígena, o que contribui para formação de políticas de aliança.

\section{REFERÊNCIAS}

ACERVO do Projeto de Extensão História e Cultura Kaingang em territórios da Bacia Hidrográfica Taquari-Antas. Lajeado-RS: Univates. 05/11/2016 a 28/02/2017.

ALMEIDA, L. K. de. Análise antropológica das igrejas cristãs entre os Kaingang baseada na etnografia, na cosmologia e dualismo. Orientador: Oscar Calavia Sáez. 2004. 278 f., Tese (doutorado em Antropologia), UFSC, Florianópolis, 2004.

ARAÚJO, G. C. C. de. A Presença de uma Premissa Categorial: A Espacialidade nos Conceitos-Chave do Pensamento Geográfico. Geoingá, 05, 02, 3-26, 2013. Disponível em: http://periodicos.uem.br/ojs/index.php/Geoinga/article/view/21294. Acesso em: 21 jan. 2018.

BARroS, L. P.; Mazurek, R. R. de S.; Baliero, C. P. P.; Amora, P. B. C.; Sztutman, M. Etnomapeamento como instrumento de apoio à classificação da tipologia florestal nas terras indígenas Uaçá, Galibi e Juminã, no estado do Amapá. In: Anais XVI Simpósio Brasileiro de Sensoriamento Remoto - SBSR, 2013, Foz do Iguaçu, 16, 3191-3198, 2013. Disponível em: http://marte2.sid.inpe.br/col/dpi.inpe.br/marte2/2013/05.29.01.02.19/doc/p1570.pdf. Acesso em: 21 mar. 2018

BRANDÃO, C. R. Identidade e etnia: Construção da pessoa e resistência cultural. São Paulo: Brasiliense, 1986.

BRASIL. Ministério Público Federal no Rio Grande do Sul. Inquérito Civil n. 1.29.000.002074/201411. Porto Alegre, 2014. 
BUSOLLI, J. A Terra Indígena Pó Mág, Tabaí/RS, no contexto das movimentações de reterritorialidade Kaingang e busca pela garantia dos direitos constitucionais. Signos, Lajeado, 37, 02, 249-274, 2016.

CAVALCANTI, T. L. V. Etno-história e história indígena: questões sobre conceitos, métodos e relevância da pesquisa. História, São Paulo, 30, 01, 349-371, jan./jun. 2011.

CODEVAT. Conselho de Desenvolvimento do Vale do Taquari. Plano estratégico de desenvolvimento do Vale do Taquari 2015- 2030. Lajeado: Ed. da Univates, 2017. Disponível em: http://planejamento.rs.gov.br/upload/arquivos/201710/11104740-plano-valedotaquari.pdf. Acesso em: 31 de out. de 2018.

COLUCCI, D. G.; Souto, M. M. M.. Espacialidades e territorialidades: conceituação e exemplificações. Geografias, Belo Horizonte, 07, 01, 114-127, jan./jun. 2011.

DIÁRIO de 16/01/2017. Pesquisa na Terra Indígena Pó Mág no Vale do Taquari. Projeto de Extensão História e Cultura Kaingang em territórios da Bacia Hidrográfica Taquari-Antas. Lajeado. Univates. 16 de jan. 2017.5 p.

DIÁRIO de 06/06/2017. Pesquisa na Terra Indígena Pó Mág no Vale do Taquari. Projeto de Extensão História e Cultura Kaingang em territórios da Bacia Hidrográfica Taquari-Antas e Projeto de Pesquisa Identidades Étnicas em espaços territoriais da Bacia Hidrográfica Taquari-Antas/RS. Lajeado. UNIVATES. 06 de jun. 2017.3 p.

DIÁRIO de 25/08/2017. Pesquisa na Terra Indígena Pó Mág no Vale do Taquari. Projeto de Extensão História e Cultura Kaingang em territórios da Bacia Hidrográfica Taquari-Antas e Projeto de Pesquisa Identidades Étnicas em espaços territoriais da Bacia Hidrográfica Taquari-Antas/RS. Lajeado. Univates. 25 de ago. 2017.4 p.

DIÁRIO de 27/10/2017. Pesquisa na Terra Indígena Pó Mág no Vale do Taquari. Projeto de Extensão História e Cultura Kaingang em territórios da Bacia Hidrográfica Taquari-Antas e Projeto de Pesquisa Identidades Étnicas em espaços territoriais da Bacia Hidrográfica Taquari-Antas/RS. Lajeado. Univates. 27 de out. 2017.4 p.

DIÁRIO de 14/12/2017. Pesquisa na Terra Indígena Pó Mág no Vale do Taquari. Projeto de Extensão História e Cultura Kaingang em territórios da Bacia Hidrográfica Taquari-Antas e Projeto de Pesquisa Identidades Étnicas em espaços territoriais da Bacia Hidrográfica Taquari-Antas/RS. Lajeado. Univates. 14 de dez. 2017. 3 p. 
DIÁRIO de 08/03/2018. Pesquisa na Terra Indígena Pó Mág no Vale do Taquari. Projeto de Extensão História e Cultura Kaingang e Projeto de Pesquisa Identidades Étnicas em espaços territoriais da Bacia Hidrográfica Taquari-Antas/RS. Lajeado. Univates. 08 de mar. 2018. 3 p.

DIÁRIO de 05/04/2018. Pesquisa na Terra Indígena Pó Mág no Vale do Taquari. Projeto de Extensão História e Cultura Kaingang e Projeto de Pesquisa Identidades Étnicas em espaços territoriais da Bacia Hidrográfica Taquari-Antas/RS. Lajeado. Univates. 05 de abr. 2018. 2 p.

DIÁRIO de 07/04/2018. Pesquisa durante a realização do Kikikoi na Terra Indígena Foxá. Projeto de Extensão História e Cultura Kaingang e Projeto de Pesquisa Identidades Étnicas em espaços territoriais da Bacia Hidrográfica Taquari-Antas/RS. Lajeado. Univates. 07 de abr. 2018.7 p.

DIÁRIO de 04/05/2018. Pesquisa na Terra Indígena Pó Mág no Vale do Taquari. Projeto de Extensão História e Cultura Kaingang e Projeto de Pesquisa Identidades Étnicas em espaços territoriais da Bacia Hidrográfica Taquari-Antas/RS. Lajeado. Univates. 04 de mai. 2018. 2 p.

DIÁRIO de 24/05/2018. Pesquisa na Terra Indígena Pó Mág no Vale do Taquari. Projeto de Extensão História e Cultura Kaingang e Projeto de Pesquisa Identidades Étnicas em espaços territoriais da Bacia Hidrográfica Taquari-Antas/RS. Lajeado. Univates. 24 de mai. 2018. 1 p.

DIÁRIO de 06/06/2018. Pesquisa na Terra Indígena Pó Mág no Vale do Taquari. Projeto de Extensão História e Cultura Kaingang e Projeto de Pesquisa Identidades Étnicas em espaços territoriais da Bacia Hidrográfica Taquari-Antas/RS. Lajeado. Univates. 06 de jun. 2018. 4 p.

DIÁRIO de 06/09/2018. Pesquisa na Terra Indígena Pó Mág no Vale do Taquari. Projeto de Extensão História e Cultura Kaingang e Projeto de Pesquisa Identidades Étnicas em espaços territoriais da Bacia Hidrográfica Taquari-Antas/RS. Lajeado. Univates. 06 de set. 2018.3 p.

DIÁRIO de 19/10/2018. Pesquisa na Terra Indígena Topẽ Pẽn no Vale do Taquari. Projeto de Extensão História e Cultura Kaingang em territórios da Bacia Hidrográfica Taquari-Antas e Projeto de Pesquisa Identidades Étnicas em espaços territoriais da Bacia Hidrográfica Taquari-Antas/RS. Lajeado. Univates. 19 de out. 2018.4 p.

ENTREVISTA Oral 1 [26 de abr. 2018, 09 p.]. Gestora da pasta indígena na $3^{\text {a }}$ Coordenadoria Estadual de Educação. Entrevistador: Jonathan Busolli. Estrela (RS): s.e., 2018. Gravação em máquina digital. Entrevista concedida ao Projeto de Extensão História e Cultura Kaingang em territórios da Bacia Hidrográfica Taquari-Antas e Projeto de Pesquisa Identidades étnicas em espaços territoriais da Bacia Hidrográfica Taquari-Antas. Lajeado: Univates. 2018.

ENTREVISTA Oral 2 [06 de set. 2018, 04 p.]. Terra Indígena Pó Mág, Tabaí/RS. Entrevistador: Jonathan Busolli. Tabaí (RS): s.e., 2018. Gravação em máquina digital. Entrevista concedida ao Projeto 
de Extensão História e Cultura Kaingang em territórios da Bacia Hidrográfica Taquari-Antas e Projeto de Pesquisa Identidades étnicas em espaços territoriais da Bacia Hidrográfica Taquari-Antas. Lajeado: Univates. 2018.

ENTREVISTA Oral 3 [06 de set. 2018, 03 p.]. Terra Indígena Pó Mág, Tabaí/RS. Entrevistador: Jonathan Busolli. Tabaí (RS): s.e., 2018. Gravação em máquina digital. Entrevista concedida ao Projeto de Extensão História e Cultura Kaingang em territórios da Bacia Hidrográfica Taquari-Antas e Projeto de Pesquisa Identidades étnicas em espaços territoriais da Bacia Hidrográfica Taquari-Antas. Lajeado: Univates. 2018.

ENTREVISTA Oral 4 [23 de fev. 2018, 02 p.]. Morador vizinho da Terra Indígena Pó Mág, Tabaí/RS. Entrevistadores: Jonathan Busolli, Fabiane Prestes, Emeli Lappe e Ernesto Bastos. Tabaí (RS): s.e., 2018. Gravação em máquina digital. Entrevista concedida ao Projeto de Extensão História e Cultura Kaingang e Projeto de Pesquisa Identidades étnicas em espaços territoriais da Bacia Hidrográfica Taquari-Antas. Lajeado: univates. 2018.

ENTREVISTA Oral 5 [23 de fev. 2018, 06 p.]. Enfermeira chefe da Secretária de Saúde de Tabaí/RS. Entrevistadores: Jonathan Busolli, Fabiane Prestes, Emeli Lappe e Ernesto Bastos. Tabaí (RS): s.e., 2018. Gravação em máquina digital. Entrevista concedida ao Projeto de Extensão História e Cultura Kaingang em territórios da Bacia Hidrográfica Taquari-Antas e Projeto de Pesquisa Identidades étnicas em espaços territoriais da Bacia Hidrográfica Taquari-Antas. Lajeado: Univates. 2018.

ENTREVISTA Oral 6 [06 de jun. 2018, 03 p.]. Comerciante de Tabaí/RS. Entrevistador: Jonathan Busolli. Tabaí (RS): s.e., 2018. Gravação em máquina digital. Entrevista concedida ao Projeto de Extensão História e Cultura Kaingang em territórios da Bacia Hidrográfica Taquari-Antas e Projeto de Pesquisa Identidades étnicas em espaços territoriais da Bacia Hidrográfica Taquari-Antas. Lajeado: Univates. 2018.

ESPINDOLA, H. S. Sociedade, natureza e território: contribuição para a história ambiental. In. Nodari, E. S.; KLUG, João. (org.). História Ambiental e Migrações. São Leopoldo: Oikos Editora, p. 167-197, 2012. . A problemática espacial e a história ambiental. Revista de História Regional. v. 20, n. 02, p. 343-374, 2015.

HAESBAERT, R. Da desterritorialização à multiterritorialidade. In: Anais do X Encontro de Geógrafos da América Latina. São Paulo, 2005.

LAROQUE, L. F. da S. Os Kaingangues: Momentos de Historicidade Indígenas. In. Boeira, N.; Golin, T.. (org.). Povos indígenas - Volume 5. Passo Fundo: Méritos Editora, p. 81-108, 2009. 
LEITE, A. F. O Lugar: Duas Acepções Geográficas. Anuário do Instituto de Geociências - UFRJ, 21, 9-20, 1998.

LIBERMANN, Z. Tempo, memória e ressignificação. Revista brasileira de Psicoterapia. v. 15, 03, 8390, 2014.

LITTLE, P. E. Territórios Sociais e Povos Tradicionais no Brasil: Por Uma Antropologia da Territorialidade. Série Antropologia, Brasília, 322, 2002.

KREUTZ, M. R.; Machado, N. T. G. O povoamento do Vale do Taquari, Rio Grande do Sul. Lajeado: Editora da UNIVATES, 2017.

MACHADO, Meline. Mapeamento Cultural e Gestão Territorial de Terras Indígenas: O uso dos Etnomapas. Orientador: Valdir Adilson Steinke. Coorientador: Rafael Sanzio Araujo dos Anjos. 2014. 119 f. Dissertação (Mestrado em Geografia). Universidade de Brasília. Brasília. 2014

MORAIS, V. S.; Bethonico, M. B. de M.; Repetto, M. Mapeamento Participativo e Gestão do Território da Comunidade Indígena Ilha. In: Anais XV Encuentro de Geógrafos de América Latina, 2015. Disponível em: http://observatoriogeograficoamericalatina.org.mx/egal15/Geografiasocioeconomica/Geografiacultural /15.pdf. Acesso em: 21 mar. 2018.

PRESTES, F. da S. O bem viver Kaingang: as conexões entre os princípios da teoria do buen vivir e os saberes tradicionais que orientam o seu modo de ser. Orientador: Luís Fernando da Silva Laroque. 2018. 279 f. Tese (Doutorado Ciências em Ambiente e Desenvolvimento). Univates, Lajeado. 2018.

RAMOS, A. W. Espaço-tempo na cidade de São Paulo: historicidade e espacialidade do "bairro" da água branca. Revista do Departamento de Geografia, 01, 65-75, 1982.

ROSA, R. R. G. da. O território Xamânico Kaingang vinculado às Bacias Hidrográficas e à Floresta de Araucária. Cadernos do LEPAARQ, v. 02, n. 04, p.101-117, 2005.

SANTOS, M. A natureza do espaço: técnica e tempo, razão e emoção. São Paulo: HUCITEC, 1996. . Técnica, espaço, tempo: globalização e meio técnico-científico informacional. São Paulo: HUCITEC, 1994.

TABAÍ. Câmara de Vereadores do Município de Tabaí. Ata da sessão ordinário de 20 de julho de 2016, 2016. Disponível em: https://tabai.rs.leg.br/site/plenaria/index/bcid/53/?sessoes-plenarias.html. Acesso em: 20 dez. 2017.

- Câmara de Vereadores do Município de Tabaí. Atas das Sessões da Câmara de Vereadores do Município de Tabaí, 2017. Disponível em: https://tabai.rs.leg.br/site/plenaria/index/bcid/53/?sessoesplenarias.html. Acesso em: 20 dez. 2017. 
TOMMASINO, K. A história dos Kaingang da bacia do Tibagi: uma sociedade Jê Meridional em movimento. Orientador: Margarita Maria Moura. 1995. 351 f. Tese (Doutorado em Antropologia). USP, São Paulo. 1995.

- Reflexões sobre a territorialidade Kaingang e a importância da inter-trans-disciplinaridade. Revista do Museu de Arqueologia e Etnologia, 27, 121-134, 2016.

TUAN, Y. Espaço, Tempo, Lugar: Um Arcabouço Humanista. Geograficidade, 01, 01, 2011.

URIARTE, U. M. O que é fazer Etnografia para os Antropólogos. Ponto Urbe (Online), 11, 01-14, 2012. Disponível em: http://pontourbe.revues.org/300. Acesso em: 18 ago. 2017.

VANSINA, J. A tradição oral e sua metodologia. In. Ki-Zerbo, J. (org.). História geral da África I: Metodologia e pré-história da África. Brasília: UNESCO, p. 139-166, 2010. 